\title{
Conceitos fundamentais para leitura do campo esportivo pela perspectiva teórica bourdieusiana
}

\author{
Igor Alexandre Silva Bueno \\ Wanderley Marchi Júnior ${ }^{2}$ \\ Recebido em maio de 2019 \\ Aceito em outubro de 2019
}

\begin{abstract}
RESUMO
O esporte é um dos fenômenos socioculturais que mais se transforma na sociedade atual. Suas mudanças ocorrem em processo contínuo e estão atreladas diretamente à sociedade em que se insere. Por essa razão, compreender o lugar das atividades esportivas contribui de forma significativa para uma possível interpretação da realidade social, visto que elas abrangem vários setores como a saúde, educação, o mundo dos negócios, entre outros. Nesse sentido, o propósito deste artigo - apoiado pela CAPES - é apresentar, mediante a pesquisa bibliográfica, os principais conceitos bourdieusianos para análise e interpretação do campo esportivo contemporâneo. Destacamos que essa é uma dentre muitas possíveis leituras teóricas das manifestações esportivas. Entretanto, percebemos que a perspectiva analítica de Pierre Bourdieu preconiza uma forma particular de entender o esporte em sua totalidade e polissemia de significados.
\end{abstract}

Palavras-chave: Esporte; Teoria dos Campos; Pierre Bourdieu; Campo esportivo.

\begin{abstract}
Sport is one of the sociocultural phenomena that changes most in today's society. Their changes occur in the continuous process and are directly linked to the society in which they find themselves. For this reason, understand the place of sports activities that contribute to a possible interpretation of social reality, as they cover various sectors such as health, education, business, among others. In this sense, the objective of this article is presented, using a bibliographical research, the main Pierre Bourdieu's concepts for analysis and interpretation of the contemporary sports' field. We emphasize that this is one of the many possible theoretical readings of sports manifestations. However, we realize that Pierre Bourdieu's analytical perspective advocates a particular way of understanding sport in its initiation and polysemy of meanings.
\end{abstract}

Keywords: Sport. Field theory. Pierre Bourdieu. Sport Sociology.

${ }^{1}$ Doutorando em Sociologia pela Universidade Federal do Paraná. Pesquisador das temáticas relacionadas à Sociologia do Esporte.

2 Professor titular da Universidade Federal do Paraná. 


\section{Introdução}

esporte é um dos fenômenos sociais e culturais que mais apresenta transformações, tem sua evolução e valores atrelados à sociedade em que se insere, está em contínuo processo de constituição e reformulação. É também uma manifestação sociocultural que sofre influências múltiplas, como por exemplo, da mídia, da economia e da política (MARQUES, 2015; BARBANTI, 2012).

$\mathrm{Na}$ contemporaneidade, as atividades esportivas ocupam espaço significativo na vida das pessoas, está presente em aspectos relacionados com a saúde, a estética, o consumo, para citar alguns exemplos. A presença do esporte pode ser verificada em praticamente todas as classes sociais. É, de fato, uma atividade abrangente da vida em sociedade (STIGGER, 2002).

Devido a sua abrangência e presença nos contextos sociais, compreender o lugar do esporte contribui significativamente para a interpretação da realidade social contemporânea (RICHTER et al., 1992). Assim, para que possam ser entendidas, as atividades esportivas devem necessariamente ser contextualizadas no tempo e no espaço em que estão presentes, levando em consideração suas múltiplas dimensões.

O sociólogo do esporte Jay Coakley (2008) afirma que ao se estudar o esporte é possível compreender tanto suas diferentes formas de manifestação quanto os valores transmitidos aos sujeitos que dele faz uso, bem como as interações estabelecidas entre os agentes e a sociedade. Assim como outras produções culturais humanas, a exemplo da música e das artes, o esporte tem uma elasticidade semântica que varia a depender onde ele ocorre e está inserido, o sentido atribuído e a forma como é percebido (COAKLEY, 2008).

A partir dessa premissa, a intenção deste trabalho é apresentar os principais conceitos operacionais da teoria bourdieusiana bem como a sua interpretação a respeito dos esportes como elementos para uma possível leitura e interpretação do campo esportivo.

Parte-se do entendimento de que o esporte pode ser pensado e tratado como uma construção social que tende a incorporar condições existentes no meio social 
(COAKLEY, 2008). Além disso, o esporte é compreendido como uma: "atividade física, construída e determinada a partir de contextos socioculturais, em constante desenvolvimento, e em franco processo de mercantilização, profissionalização, popularização e espetacularização”. (MARCHI JÚNIOR, 2004, p. 24).

Para a realização deste trabalho, o procedimento metodológico empregado se baseia em uma revisão bibliográfica do referencial teórico à sociologia do esporte, mais precisamente as obras de Pierre Bourdieu. Foram reunidos textos que apresentam e articulam alguns dos conceitos e ideias que possam oferecer um quadro teórico capaz de proporcionar uma análise do campo esportivo. As contribuições da produção de Bourdieu proporcionam reflexões acerca das diferentes possibilidades de apropriação e usos de seus conceitos e teoria, em especial aos pesquisadores ligados a áreas que investigam as atividades esportivas, recreativas e de lazer. Nesse sentido, a assimilação das reflexões do teórico francês possibilita maior clareza nas escolhas e relações entre o aporte teórico eleito e os usos de outros conceitos e autores aos quais se recorre no processo de pesquisa na sociologia do esporte.

As obras foram selecionadas basicamente devido a sua importância para as ciências sociais como um todo, e por conter definições dos conceitos bourdiesianos mais utilizados nas pesquisas relacionadas à sociologia do esporte, possibilitando assim a articulação entre trabalho empírico e reflexão teórica. A seleção dos conceitos foi baseada em dois critérios: 1) os conceitos fundamentais da teoria dos campos de Bourdieu e 2) os conceitos que têm operacionalização explicativa no universo esportivo. Com isso, foi possível apresentar conceitos que procuram compreender e explicar como os espaços sociais são constituídos, reproduzidos e transformados.

Outros textos, artigos e livros de comentadores também serviram como referencial teórico. A escolha de tais comentadores tem relação com a influência exercida por Pierre Bourdieu não somente sobre os pensadores franceses, mas sobre os intelectuais de vários países, pertencentes a outras disciplinas das ciências humanas e sociais da educação física. Além disso, os autores escolhidos são referência para a área devido a apropriação teórica das obras de Bourdieu. Com isso, foi possível apreender aspectos importantes a respeito da perspectiva teórica, dos conceitos e da visão 
bourdiesiana relacionada ao esporte sem que existissem interpretações equivocadas que pudesse deturpar o sentido original proposto pelo teórico francês.

\section{Pierre Bourdieu e sua base e perspectiva teórica}

Pierre Bourdieu evidenciou em suas análises a existência de um jogo de dominação e reprodução de valores em diferentes esferas da sociedade que gera formas de distinção social entre grupos (MARQUES; GUTIERREZ, 2014). O resultado do seu trabalho em reunir e retrabalhar conceitos do racionalismo de Bachelard, do materialismo de Marx, do neokantiano sobre as formas simbólicas de Durkheim e da visão agonística de Weber, culminou em um quadro teórico original que possibilitava desvendar a multifacetada dialética das estruturas sociais e mentais no processo de dominação (WACQUANT, 1992).

Suas investigações não se restringiram somente ao espaço social, também aplicou seu método em diferentes campos como a arte, ciência, mídia, educação, esporte, dentre outros. Nos anos de 1960, Bourdieu foi considerado um "rebelde da elite intelectual", pois apresentava visões diferenciadas que chocavam com o pensamento da época. Além de ter métodos de análise e conceitos operacionais originais, o acadêmico mostrou-se transgressor das divisões disciplinares, o que gerou, com certa frequência, reações críticas aos seus trabalhos (SOUZA; MARCHI JÚNIOR, 2017).

Tendo suas publicações de impacto nas décadas de 1960 e $1970^{3}$, o autor se destacou devido a sua originalidade e metodologia de investigação. Durante esse período, Bourdieu foi implacável no combate às correntes de análises semiológicas e das estéticas formalistas (MARQUES, 2015). O seu cuidado e a expansão intelectual crítica, juntamente com a qualidade e coerência conceitual com que elaborou seus estudos, fez de Pierre Bourdieu um dos maiores sociólogos de sua época (MARCHI JÚNIOR, 2004).

3 Os argelinos, 1962; Os herdeiros, 1964; Uma arte média, 1965; O amor da arte, 1966, A reprodução, 1970; Esboço de uma teoria da prática, 1972; A distinção, 1979. 
Seu pensamento estruturou-se pautado no conhecimento praxiológico que tem como fundamento estabelecer um sistema de relações objetivas e subjetivas de forma dialética entre disposições e estrutura. É, por sua vez, uma forma de saber que busca superar a dicotomia existente entre análises objetivistas e subjetivistas. Sua forma de pensar configura-se em uma estratégia que procura se desvencilhar das limitações dos pressupostos estruturalistas e das concepções advindas da fenomenologia (WACQUANT, 1992).

Para Bourdieu é perceptível que os indivíduos das sociedades - arcaicas e complexas - não são apenas autômatos regulados como relógios, que obedecem a leis mecânicas que lhes escapam, pelo contrário, são agentes de suas realidades e tem, em certa medida, o poder de transformar suas condições e posições dentro de um contexto social (BOURDIEU, 1990).

Diferentemente da percepção mecânica e rígida do estruturalismo francês, Bourdieu sustenta uma reflexão genérica, sem resposta dogmática proveniente de uma visão unidimensional. Por esse motivo, seu pensamento busca articular o ator e a estrutura social para a compreensão das relações sociais ligadas às disputas por poder em diferentes campos da sociedade, considerando as estruturas objetivas, de espaço, de regras e de normas, em uma relação de constante intercalação com questões subjetivas, de anseios, história individual e significação por parte dos sujeitos (SOUZA; MARCHI JÚNIOR, 2017).

Segundo Bourdieu o conhecimento fenomenológico - as correntes ligadas a etnometodologia e ao interacionismo simbólico - captava somente a experiência imediata do mundo social, ou seja, as percepções ligadas ao dia-a-dia do indivíduo. $\mathrm{O}$ teórico ressalta que esses saberes excluíam a possibilidade de entender, principalmente, as condições estruturais que permitiam a experiência e existência da subjetividade. A crítica tecida por ele a respeito da fenomenologia refere-se, basicamente, que essa teoria descreve as ações e interações sociais e não questiona a respeito das condições objetivas que poderiam explicar o curso das interações. As críticas do autor vão além no sentido de que todas essas abordagens não captavam as bases sociais que supostamente condicionariam as experiências práticas, além de criar 
uma concepção ilusória do mundo social com excessiva autonomia e consciência dos sujeitos (BOURDIEU; WACQUANT, 1992; CATANI et al., 2017).

Por outro lado, em contraposição às ideias subjetivistas, o conhecimento objetivista tem por característica a ruptura com as experiências subjetivas imediatas. Segundo essa abordagem, primeiro investiga-se as estruturas sociais que organizam ação do indivíduo para depois compreender a experiência subjetiva, deixando de lado a concepção de que os seres sociais têm consciência de suas ações. A preocupação e crítica de Bourdieu focam-se desta vez na tendência que o objetivismo teria de conceber a prática como mera execução de regras estruturais dadas, sem se interessar pelo processo de produção e reprodução das regularidades sociais executadas pelos agentes por meio de suas ações práticas (BOURDIEU; WACQUANT, 1992; CATANI et al., 2017).

Como solução a esse problema, Bourdieu buscou uma forma de conhecimento baseado na prática. Esse saber articula dois planos, o da ação e o da estrutura para fazer a leitura da complexidade do mundo social. O teórico propõe uma reflexão que representava a interiorização da exterioridade e a exteriorização da interioridade, numa relação dialética que buscava evidenciar a passagem do produto para o princípio de produção da prática. Com isso, busca superar as oposições tradicionais na Sociologia - subjetivismo/objetivismo, teoria/empiria, holismo/individualismo (BONNEWITZ, 2003).

Por conta dessa percepção, o entendimento praxiológico de Bourdieu tem por base as perspectivas teóricas "construtivismo estruturalista" ou "estruturalismo construtivista” como aponta o trecho:

Por estruturalismo ou estruturalista, quero dizer que existem, no próprio mundo social e não apenas nos sistemas simbólicos - linguagem, mitos, etc-, estruturas objetivas, independentes da consciência e da vontade dos agentes, as quais são capazes de orientar ou coagir suas práticas e representações. Por construtivismo, quero dizer que há, de um lado, uma gênese social dos esquemas de percepção, pensamento e ação que são constitutivos do que chamo de habitus e, de outro, das estruturas sociais, em particular do que chamo de campos e grupos, e particularmente do que se costuma chamar de classes sociais (BOURDIEU, 1990, p. 149). 
Com essa definição, o pensador trás uma nova proposição teóricometodológica e procura preencher as lacunas deixadas pelas perspectivas anteriores. Bourdieu propõe então relacionar as abordagens dialeticamente, (BOURDIEU, 1996). Para isso adota uma série de conceitos e instrumentos que servem como ferramentas investigativas para pensar e analisar as diferenças e posições dos grupos e suas relações, sobretudo, na tendência à reprodução da ordem social (BONNEWITZ, 2003).

\section{Principais conceitos bourdieusianos}

Com o objetivo de erguer uma teoria que pudesse compreender a realidade conflituosa, forjou ferramentas analíticas que ajudam a entender os espaços relativamente autônomos permeados por forças objetivas e lutas por dominação (BOURDIEU; WACQUANT, 1992).

Assim, para que fosse possível a aplicação de sua perspectiva, surge à necessidade de delimitar um espaço característico onde ocorrem as interações sociais (BOURDIEU; WACQUANT, 1992). É a partir dessa premissa, que nasce a noção de campo social, uma ferramenta de análise que permite a delimitação do objeto de pesquisa. Com o conceito de campo Bourdieu pretende propor formas gerais de pensar nossas sociedades. E é a partir daí que o autor constrói a Teoria dos Campos. A respeito do campo ele escreve:

O cosmo social é constituído pelo conjunto desses microcosmos sociais relativamente autônomos, espaços de relações objetivas que são o lugar de uma lógica e de uma necessidade específica e irredutíveis àquelas que regem os outros campos. Por exemplo, o campo artístico, o campo religioso ou o campo econômico obedecem a lógicas diferentes [...] (BOURDIEU; WACQUANT, 1992, p. 73).

Bourdieu cunha uma definição de campo como um espaço relativamente autônomo, um microcosmo dotado de leis próprias, incluído no macrocosmo (leis gerais da sociedade). O campo também é caracterizado pela existência de desigualdade de posses e acesso a bens (os capitais). É um lugar de embate, lutas de forças pela 
aquisição de poder simbólico. Há, dessa forma, em cada campo, regras de jogo e desafios particulares que são sempre específicos a cada campo (BOURDIEU, 1983).

Para o teórico, campo é um "sistema" ou um "espaço" estruturado de posições ocupadas pelos diferentes indivíduos (agentes) com distintas posições, que buscam a posse do poder simbólico - conferindo reconhecimento e legitimidade aos detentores desses aspectos desejados no campo (BOURDIEU, 1983). A estrutura do campo é estabelecida pelo estado de relação de força entre os agentes e instituições engajadas na luta, como também pelo resultado dos embates anteriores os quais orientam as estratégias posteriores. O objetivo maior é o acúmulo de capital específico (BOURDIEU; WACQUANT, 1992).

En términos analítocos, un campo puede definirse como una red o configuración de relaciones objetivas entre posiciones. Estas posiciones se definen objetivamente en su existencia y en las determinaciones que imponen a sus ocupantes, ya sean agentes o instituciones, por su situación (situs) actual y potencial em la estructura de la distribuición de las diferentes especies de poder (o de capital) - cuya posesión implica el acceso a las ganancias específicas que están em juego dentro del campo - y, de paso, por sus relaciones objetivas con las demás posiciones (dominación, subordinación homología, etc.) (BOURDIEU; WACQUANT, 1992, p. 64).

Como apontado por Bourdieu e Wacquant (1992), essas são, sinteticamente, as características de todo campo, ou seja, as "lei gerais dos campos". Analogicamente, pode-se considerar um campo como um mercado em que os agentes se comportam como jogadores que buscam a posse de determinados capitais que possibilitem a dominação do campo (BONNEWITZ, 2003).

Agente, por sua vez, é definido como indivíduo ou instituição inserido em uma posição determinada do espaço social portador de um conjunto específico de disposições incorporadas (habitus) que age dentro de certo espaço social (BOURDIEU, 1990).

Entre as táticas de ação do agente existem duas possibilidades, a de conservação e as de subversão. A primeira forma se refere a uma posição dos dominantes, os quais buscam a manutenção da ordem já estabelecida, enquanto a segunda, corresponde à posição dos dominados que procuram contrapor à lógica existente (BOURDIEU, 1990). A partir dessas duas posições, são travados dentro do 
campo embates entre situações antagônicas, por exemplo, entre velhos e novos, ortodoxos e heterodoxos, conservadores e revolucionários etc. (MARQUES, 2015).

De acordo com Bourdieu (1990), as divisões entre dominantes e dominados podem ao mesmo tempo estar reconhecidas e ignoradas, a depender da posição que estão. Além disso, aos olhos das pessoas que não foram formadas no interior de determinado campo, é pouco provável que consigam identificar a estrutura e as relações existentes daquele espaço, uma vez que somente compreendem o jogo aqueles que são pertencentes ao meio em que se joga (CATANI et al., 2017).

Por meio dessa relação dialética entre campo e agentes sociais, surge um dos principais conceitos da teoria dos campos, o habitus. Este conceito é percebido pelo teórico como o princípio estruturador da percepção e das ações dos agentes dentro do campo, e tem a função de transmitir conscientemente e inconscientemente um sistema de esquemas de apreciações e de atos. Bourdieu define habitus como:

Sistemas de disposições duráveis, estruturas estruturadas predispostas a funcionar como estruturas estruturantes, isto é, princípio gerador e estruturador das práticas e das representações que podem ser objetivamente "reguladas" e "regulares" sem ser o produto da obediência a regras, objetivamente adaptadas a seu fim sem supor a intenção consciente dos fins e o domínio expresso das operações necessárias para atingi-los e coletivamente orquestradas, sem ser o produto da ação organizadora de um agente (BOURDIEU, 1983, p.61).

O habitus, segundo Bourdieu, norteia as formas de ação dos sujeitos, ou seja, a sua práxis. Esse modo de atuação é estabelecido de acordo com as leis do campo especificamente orientado para a disputa e aquisição de capital. Configura-se como o fator subjetivo de análise, pois considera as percepções e visões de mundo dos agentes, ou seja, suas individualidades, porém, não descartando a sua interação com a coletividade (BOURDIEU, 1983). Sendo assim, o habitus é considerado um modo estratégico de atuação do agente, essa forma de desenhar e desenvolver suas ações tem por base alguns elementos como: a) a posição que ele ocupa dentro do campo ou subcampo, se tal posicionamento é recente ou sofre influência de alguma forma de capital; b) o grupo social ao qual o sujeito pertence; c) a bagagem histórica e cultural do agente (BOURDIEU, 1992). 
Em síntese, o conceito de habitus concilia a oposição aparente entre realidade exterior e as realidades individuais, expressa o diálogo, a troca constante e recíproca entre o mundo objetivo e o mundo subjetivo. Ou seja, a relação de interdependência entre o conceito de habitus e o de campo é condição para seu pleno entendimento (BOURDIEU, 1992).

Além dos conceitos já apresentados, a obra de Bourdieu oferece outra ferramenta analítica que auxilia na compreensão das disputas dentro dos campos, a illusio (BOURDIEU, 1996). Esta noção configura-se como interesse, uma motivação inerente a todo agente dotado de um habitus de um determinado campo. Por definição illusio: “É 'estar em', participar, admitir, portanto, que o jogo merece ser jogado e que os alvos engendrados no e pelo fato de jogar merecem serem perseguidos; é reconhecer o jogo e o alvo". (BOURDIEU, 1996, p. 139-140) A illusio, por conseguinte, se relaciona com a crença no jogo e de se estar envolvido nele. Assim, para Bourdieu, cada campo requer e aciona uma forma de interesse, um investimento, uma illusio específica que expressa o reconhecimento tácito de seus participantes no valor do que ali está em disputa (BOURDIEU, 1996).

Nesse sentido, investir e atuar nas disputas travadas em torno de capitais, recursos simbólicos ou objetivados entendidos como atrativos de determinado espaço, são elementos fundamentais para a existência e funcionamento do campo. Isso somente é possível graças à existência e o compartilhamento da mesma illusio, da crença fundamental em seu interesse (CATANI et al., 2017). Sem o aspecto da illusio é pouco provável que agentes tenham a cumplicidade de se reunir e travar disputas em torno de algo que esteja em jogo.

Compartilhar a mesma illusio significa ter em comuns sistemas de princípios, de disposições, de expectativas, de esperanças, de classificação e de avaliação entorno de objetos em luta no campo. Em outras palavras, são disposições que se adequam e se ajustam às regularidades de um universo social específico. Este saber prático permite ao agente fazer antecipações sobre as possíveis estratégias de outros sujeitos pertencentes ao campo, permite também saber as maneiras de agir e investir ideias do jogo. São, de modo geral, tendências imanentes do campo que não são enunciadas de forma explícita (BOURDIEU, 1989). 
Por essa razão, a illusio não passa pela consciência, ela é da ação, da rotina, é uma adesão que ocorre sem o consentimento intelectual. Tem pouca ligação com o cálculo racional que prevê lucro, é mais entendida como um produto e princípio das ações práticas próprias de um espaço social delimitado. Nesse sentido, a illusio reflete um ajustamento e uma cumplicidade entre as estruturas mentais dos sujeitos, ou seja, seus habitus, e as estruturas objetivas (CATANI et al., 2017).

Capital é outra noção basilar na teoria bourdieusiana. Este conceito permite entender e analisar o espaço social como um espaço hierarquizado e permeado por desigual distribuição de recursos. Capital é definido por Bourdieu como um "recurso" que pode ser possuído por um indivíduo, um grupo, uma comunidade, um país etc. Ele pode existir em um estado subjetivo, suscetível a variações socioculturais de acordo com o julgamento de cada grupo, quanto no estado objetivo, sob a forma de bens físicos, imobiliários, pertences financeiros avaliados de acordo com o mercado (BOURDIEU, 1983, 1989).

O capital também pode se manifestar no estado incorporado, na forma de disposições inscritas nos cérebros e nos corpos, como em diplomas e certificados, carteira de habilitação, por exemplo. No estado incorporado, o capital remete ao direito e ao reconhecimento chancelado por instituições. Atua, portanto, principalmente no nível do domínio sobre as normas e os padrões vigentes (CATANI et al., 2017).

Acrescentam-se ainda quatro formas básicas de capitais, sendo três delas comuns à maioria dos campos: o econômico, o social, o cultural e o simbólico (BOURDIEU, 1983; 1989; 1998). O primeiro, capital econômico, é, sobretudo, um indicador de posição econômica. Pode ser entendido como a posse de dinheiro e poder aquisitivo (BONNEWITZ, 2003). Já o capital social corresponde à rede de relacionamentos que o agente mantém com os outros indivíduos do campo. Trata-se, desse modo, das "relações pessoais" que constituem uma "rede". Bourdieu (1998) adverte que:

O capital social é o conjunto de recursos atuais ou potenciais que estão ligados à posse de uma rede duradoura de relações mais ou menos institucionalizadas de interconhecimento e de inter-reconhecimento; ou em 
outros termos, à vinculação a um grupo, como conjunto de agentes que, além de serem dotados de propriedades comuns (passíveis de serem percebidas pelo observador, pelos outros ou por eles mesmos), estão unidos por ligações permanentes e úteis (BOURDIEU, 1998, p.2).

Esta noção evoca, sobretudo, os relacionamentos estabelecidos entre os agentes e como eles fazem uso dessa rede. Para o autor, a vinculação a um grupo, e seus efeitos, é decisivo e constitui o alicerce da solidariedade existente no campo (BOURDIEU, 1998).

O terceiro, o capital cultural, é definido como o conhecimento que o agente possui e que valoriza dentro do campo, capaz de render dividendos que proporcionam lucros a seus detentores. Este capital manifesta-se basicamente em três estados: incorporado, objetivado e institucionalizado (BOURDIEU, 1998).

O capital incorporado apresenta-se sob a forma de disposições duráveis, resultado do trabalho e experiência obtido pelo agente. Tem relação, principalmente, com o sistema de ensino, mas também liga-se ao conhecimento existente no seio familiar, ou seja, as vivências das gerações anteriores que são transmitidas, por exemplo, pela oralidade (BOURDIEU, 1998).

Objetivado, por sua vez, são materializados na posse de objetos, isto é, em quadros, livros, filme, viagens, máquinas ou instrumentos que servem e ajudam no processo de educação e incorporação cultural. Por fim, também podem aparecer em estado institucionalizado, fortemente ligado à educação formal, como diplomas, certificados e títulos que são, frequentemente, atestados e reconhecidos institucionalmente (BOURDIEU, 1998).

Além das três formas de capitais já mencionadas, há também o capital simbólico definido como uma espécie particular que oferece reconhecimento e poder ao detentor dentro de um campo específico. Esta última forma de capital toma configurações de valor e reconhecimento simbólico diverso de acordo com cada campo. É determinado pelo que as normas e costumes daquele espaço indicam como algo a ser reconhecido e posteriormente valorizado pelo grupo, também relaciona-se à 
honra, prestígios e outras formas de créditos entendidos como valiosos ou fundamentais para o campo (GIULIANOTTI, 2005 apud MARQUES, 2015).

Bourdieu ao longo de suas obras não apresenta uma definição clara e restritiva do que seria o capital simbólico, pelo fato de desconfiar das definições, julgando que tal espécie de ação seria uma maneira positivista de fazer Ciência. Outro elemento apontado pelo teórico trata-se da característica deste capital que se apoia na crença ou no reconhecimento muito variável a depender do campo e dos contextos. Este capital, em particular, tem propriedades simbólicas que somente emergem na relação com sujeitos que os percebem e apreciam, pois precisam ser interpretadas segundo sua lógica específica (habitus) que existe na e pela percepção dos agentes que compõe um determinado campo (BOURDIEU, 2001a).

No entanto, em 1994 em Toulouse na França, Bourdieu realizou uma intervenção intitulada "Anciennes et nouvelles aristocraties de 1880 à nos jours 5 ” em um colóquio, cujo texto foi publicado após sua morte por Didier Lancien e Monique SaintMartin, no qual apresenta o seu entendimento do conceito de capital simbólico:

O capital simbólico é um capital com base cognitiva que se apoia no conhecimento (não intelectual, mas um domínio prático, um senso prático). Qualquer propriedade - conchas nas ilhas Trobriand, números de voltas do colar de perolas da Suécia [...] -, qualquer diferença pode tornar-se capital simbólico, distinção, se a distinção make sense, 'adquire sentido' para as pessoas que dispõem de categorias de percepção para apreende-las (LANCIEN; SAINT-MARTIN, 2007, p. 388).

Por esta definição, Bourdieu afirma, portanto, que o capital simbólico tem propriedades bastante particulares e diferentes dos outros capitais, tem a característica de ser variável, adaptável, frágil e vulnerável e só terá sentido quando é atribuído valor por aqueles que reconhecem sua estima (LANCIEN; SAINT-MARTIN, 2007).

Em seu livro Meditações Pascalianas, Bourdieu (2001b), afirma que os três tipos (social, econômico e cultural) podem ser convertidos em capital simbólico. Isso vai depender do volume de capital e da importância que tal capital tem dentro do campo, ele pode ser convertido em sinônimo de distinção que confere poder. Por isso,

${ }^{4}$ GIULIANOTTI, R. Sport: a critical sociology. Bodmin: MPG Book, 2005.

5 Tradução nossa: "Velhas e novas aristocracias de 1880 até hoje". 
a maioria dos capitais é convertível em capital simbólico, de acordo com as normas, interesses e agentes envolvidos nas disputas (BOURDIEU, 2001b).

Por sua vez, o acúmulo de capital simbólico permite ao seu detentor exercer a violência simbólica, que se trata da dominação consentida entre agentes do campo. Pode ser entendida como uma aceitação das regras e crenças partilhadas no campo de modo "natural". Esta forma de violência traduz o valor e o reconhecimento da legitimidade adquirida, tem o poder tanto para a manutenção quanto para a transfiguração das formas de distribuição de bens e propriedades específicas do campo (BOURDIEU, 1989).

Já para pensar a respeito da percepção e os usos do corpo, tem-se o conceito de hexis corporal. Para Bourdieu (2014), o corpo é um produto social que expressa aspectos relacionados ao habitus do indivíduo, pois sofre influência das desigualdades de capitais existentes na sociedade. Além disso, o corpo, e seu comportamento, pode expressar o grau de incorporação de determinado arbitrário cultural por parte do agente. Bourdieu pontua:

\footnotetext{
As diferenças de pura conformação são sobrepostas pelas diferenças de hexis, de "cuidado": na maneira de portar o corpo, de se portar e de se comportar, por meio da qual se exprime toda a relação com o mundo social (na medida em que a relação com o próprio corpo é, como veremos, uma maneira particular de experimentar a posição no espaço social, pela experiência da distância entre o corpo real e o corpo legítimo) (BOURDIEU, 2014, p. 248).
}

Nesse sentido, a hexis corporal (incorporada) resulta na disposição permanente, maneira durável de se portar, de falar, no tom de voz, na forma de caminhar, na postura, nas expressões, no modo de sentar-se, até mesmo na forma de manejar instrumentos e utensílios. A hexis corporal também pode relacionar-se no modo de sentir e pensar, visto que, começam a se estruturar diante das experiências vividas no campo específico de atuação. Todas essas expressões e sentimentos relacionam-se a um conteúdo de consciência singular e sistemático, são aspectos que podem aparecer inscritos na hexis corporal do agente pertencente ao campo (BOURDIEU, 2014). 
Por conseguinte, o corpo do agente carrega uma miríade de significações e de valores sociais que são moldados a ponto de formar uma hexis corporal definida e extremamente ligada às características exigidas e impostas pelo campo. A depender de cada campo, tais exterioridades começam a ser marcadas no corpo desde o nascimento. E por esse fato, os agentes são levados a se estruturarem e se reestruturar constantemente, consolidando uma hexis corporal específica (BOURDIEU, 2002).

Em síntese, esses são alguns conceitos da teoria de Bourdieu possíveis de serem usados para abordar as manifestações esportivas, visto que articula a agência e estrutura objetivo, conectando, ao mesmo tempo, a estrutura e social e a ação prática dos agentes. Tais definições quando relacionadas, podem proporcionar uma ampla visão das relações existentes entre os diversos agentes que integram o campo do esporte e das práticas corporais. (ORTIZ, 1994).

\section{O campo esportivo pela percepção de Pierre Bourdieu}

Com relação às construções teóricas feitas sobre o fenômeno esportivo, Bourdieu não se preocupou em compreender o esporte em si, mas os fatores que levam os indivíduos a socializarem e estabelecerem diferentes preferências no campo esportivo. O seu principal foco de análise tinha relação com a estratificação existente nesse espaço em especial (SOUZA; MARCHI JÚNIOR, 2017).

Bourdieu (1990) almejou elaborar um método de análise que fosse adequado às demandas do fenômeno esportivo ou das "práticas que comumente aceitamos e designamos sob a unidade nominal de esporte moderno poderiam ser lidas a partir dos preceitos que integram sua economia geral dos campos" (SOUZA; MARCHI JÚNIOR, 2017, p. 251).

O resultado desse esforço teórico-metodológico pode ser principalmente encontrado nos textos: “Como é possível ser esportivo?" (BOURDIEU, 1983) e em "Programa para uma sociologia do esporte", publicado em 1990. Em seus estudos, o teórico sugere que o universo das práticas esportivas é semelhante a outros espaços de produção cultural e material, e, por este motivo, é possível encontrar propriedades gerais desses espaços (BOURDIEU, 1983). 
No primeiro texto, Bourdieu parte da ideia de que há um conjunto de práticas e de consumos esportivos dirigidos aos agentes sociais que estão vinculadas a certa demanda social. Oriunda dessa constatação o sociólogo francês coloca duas questões para pensar a respeito do esporte:

\footnotetext{
Em primeiro lugar, existe um espaço de produção dotado de uma lógica própria, de uma história própria, no interior do qual se engendram os "produtos esportivos", isto é, o universo das práticas e dos consumos esportivos disponíveis e socialmente aceitáveis em um determinado momento? Segundo, quais são as condições sociais de possibilidade de apropriação dos diferentes "produtos esportivos" assim produzidos, prática do golfe ou do esqui, leitura de jornais esportivos, reportagem televisionada da copa do mundo de futebol? Dito de outra maneira, como se produz a demanda dos "produtos esportivos", como as pessoas passam a ter o "gosto" pelo esporte e justamente por um esporte mais que outro, enquanto prática ou enquanto espetáculo? Mais precisamente, segundo que princípios os agentes escolhem entre as diferentes práticas ou consumos esportivos que lhes são oferecidos como possibilidade em um dado momento? (BOURDIEU, 1983, p. 136).
}

No livro "A distinção: crítica social do julgamento" - de 1979 - Bourdieu também dedica algumas páginas no exame das manifestações esportivas (BOURDIEU, 2006). Neste texto, em específico, o autor relaciona o sentido das práticas esportivas com os gostos de classe e os estilos de vida.

Bourdieu sugere que as variações nas formas e nas práticas esportivas segundo grupos sociais referem-se às variações da percepção e de apreciação das vantagens, imediatas ou diferenciais que elas podem proporcionar ao agente, sejam elas no sentido econômico, cultural ou corporal. Configurando formas de distinção, de classificação, que sinalizam distâncias ou proximidades entre grupos. (BOURDIEU, 2006).

Essa versatilidade, por assim dizer, é fruto de distintos habitus, gostos, lucros e custos intrínsecos e extrínsecos da atividade, simboliza a diferenciação das posições sociais mais ou menos privilegiadas. (BOURDIEU, 1990; STIGGER, 2002; BOURDIEU, 2006). Visto desta maneira, as manifestações esportivas deixam de ser analisadas de forma homogênea e passam a ser percebidas em um sentido heterogêneo, diverso, pautado em uma relação não consensual de dominação e de embate. (BOURDIEU, 1990; BOURDIEU, 2006). 
Por ter essas características singulares, o campo esportivo não é estático, é dinâmico e está em constante interação com outros espaços sociais. Os outros campos (econômico, político, intelectual, por exemplo) ainda que distintos do campo esportivo preenchem o esporte de significados e o influenciam, ao mesmo tempo que o esporte mantém certas lógicas específicas. Há, nesse sentido, um processo de autonomização, em um sistema regido por leis próprias que constituem o campo esportivo, que o diferencia dos demais (BOURDIEU, 1990).

O campo esportivo é diferenciado por ser um espaço social relativamente autônomo, pois tem seu próprio tempo, suas regras de funcionamento singulares, seus atores sociais, suas lutas e seus capitais em disputa específicos. Dessa forma, tem-se um microcosmo dotado de características que lhe dão um caráter distintivo, porém com estrutura bastante semelhante ao macrocosmo social. A autonomia relativa do campo a que Bourdieu se refere, trata-se dá sua capacidade de refratar às pressões ou demandas externas: "quanto mais autônomo for um campo, maior será seu poder de refração”. (BOURDIEU, 1997, p. 22).

Cabe frisar que o grau de autonomia dos campos pode ser deduzido a partir da distribuição e tipos de capitais que orientam as relações no interior do campo (BOURDIEU, 1983). Essa autonomia relativa também pode relacionar-se com o capital simbólico acumulado no decorrer do tempo (BOURDIEU, 1996).

O modelo relacional de análise do campo esportivo sistematizado por Bourdieu ao longo dos textos que versam sobre essa temática apresentam duas proposições importantes para pensar as manifestações esportivas. A primeira delas consiste em pensar um esporte em relação às outras práticas esportivas. Segundo o autor, não é possível desenvolver uma análise sem relacionar com os demais esportes que compõem o campo.

A segunda recai sobre a necessidade de contextualizar as práticas esportivas e o espectro de representações e signos sociais a elas associadas como um resultado do encontro entre a oferta dos bens esportivos e a demanda desses mesmos bem. Deve-se levar em consideração, mediação entre a oferta esportiva exteriorizada no campo e as disposições inscritas nos agentes, ou seja, a demanda (BOURDIEU, 1983). 
Trata-se, portanto, de reconstruir o campo esportivo tendo por base os pressupostos de uma economia simbólica existente dentro do microcosmo analisado com o fim de entender como está estabelecida a estrutura de poder. Agindo assim, é possível desenvolver uma investigação que tenha como objeto sociológico o esporte. (MARCHI JÚNIOR, 2004)

Tal teoria amplia as possibilidades de leitura do fenômeno esportivo que tratam da relação e disputa entre amadorismo versus profissionalismo, a respeito da mercantilização, popularização, usos e sentidos do esporte, consumo e prática, o desenvolvimento do espetáculo de entretenimento esportivo (MARCHI JÚNIOR, 2002, 2004) como também dos usos do corpo no esporte (SALVINI et al., 2012) para citar alguns possíveis desdobramentos.

\section{Considerações finais}

Segundo a visão de Pierre Bourdieu é pouco provável captar a real lógica de um campo social sem mergulhar empiricamente em suas particularidades e relacionálas com a história e com outros fatos que o permeiam (BOURDIEU, 1996). Por este motivo, sua teoria é estruturada em uma relação dialética entre aspectos objetivos e subjetivos que visa articular as estruturas dadas e a subjetividade existente na relação dos agentes.

Com esse movimento Bourdieu busca observar e trazer à tona a dinâmica e as lógicas de reprodução e dominação no interior dos diversos campos como, por exemplo, o político, o econômico, o midiático, o artístico, o educacional, o religioso, o esportivo, dentre outros. Assim, para que seja possível a realização desse empreendimento, é fundamental ter a compreensão de alguns conceitos. Neste sentido, este artigo propôs apresentar seu esquema teórico-conceitual expresso na tríade "campo + habitus + capital" como também outros conceitos importantes para pensar possíveis reflexões sob o campo esportivo. A forma dinâmica com que os conceitos se inter-relacionam gera a uma percepção eminentemente reflexiva de articulação entre as dimensões empírico-teóricas que traz à tona as lutas e as tensões 
particulares de cada espaço sem desconectar do todo social (SOUZA; MARCHI JÚNIOR, 2017).

Ao fazer aproximações de seus conceitos com o campo esportivo, foi possível perceber a relevância e pertinência da teoria para área das temáticas que envolvem o esporte. Em suma, ao longo dessas aproximações, o teórico reivindica uma sociologia científica do esporte de caráter não substancialista, como um fim em si mesmo, tampouco quer reduzir suas propriedades aos imperativos de uma história política e econômica. O que Bourdieu busca é (re)construir estruturalmente a história dos bens e das práticas esportivas considerando esse espaço e suas particularidades relacionados com os demais campos sociais (SOUZA; MARCHI JÚNIOR, 2017).

Com resultado de suas investigações Bourdieu teceu críticas contundentes dirigidas ao fenômeno esportivo. Uma delas se refere ao caráter violento que os esportes espetacularizados têm tomado. Segundo Bourdieu (1990), o esporteespetáculo apresenta uma distância entre a prática e o consumo muito acentuado. É notório para Bourdieu a vinculação dos agentes a um tipo passivo e televisionado de consumo dos esportes e dos produtos relacionados a ele (BOURDIEU, 1990).

Outra crítica versa sobre o campo esportivo retraduzir as distâncias sociais. Pela ótica de Bourdieu, o esporte reifica e veicula códigos de distanciamento que reforçam por meio de uma série de atributos e preceitos considerados legítimos e ilegítimos, superiores e inferiores, pertencentes a uma elite restrita ou então a uma massa heterogênea identificada comumente com aquilo que se entende por popular. Em suma, "o esporte e os bens culturais correlatos se tratam de práticas objetivamente classificadas e com potencialidade a se converter em práticas classificadoras, isto é, a se tornarem um lucro e expressão simbólica da condição de classe" (SOUZA; MARCHI JÚNIOR, 2010, p. 308).

Assim, diante do contexto apresentado cabe aos sociólogos do esporte operacionalizar os conceitos de Bourdieu para gerar análises que restituem empiricamente as lutas e as tensões particulares ao campo esportivo. 


\section{Referências}

BARBANTI, V. J. Dicionário de educação física e do esporte. Barueri: Manole, 2012.

BONNEWITZ, P. Primeiras lições sobre a sociologia de P. Bourdieu. Petrópolis: Vozes, 2003.

BOURDIEU, P. A cultura está em perigo. In: BOURDIEU, P. Contrafogos 2: por um movimento social europeu. Rio de Janeiro: Zahar, 2001 .

BOURDIEU, P. Coisas ditas. São Paulo: Brasiliense. 1990.

BOURDIEU, P. Como é possível ser esportivo. In: BOURDIEU, P. Questões de sociologia. Rio de Janeiro: Marco Zero, 1983. p. 136-153.

BOURDIEU, P. L'espace des sports-1. Actes de la Recherche en Sciences Sociales, Paris, v. 79, p. 2-115, 1989.

BOURDIEU, P. Meditações pascalianas. Rio de Janeiro: Bertrand Brasil, 20oıb.

BOURDIEU, P. Notas provisórias sobre a percepção social do corpo. Pro-Posições, São Paulo, v. 25, n. 1, p. 247-256, 2014.

BOURDIEU, P. O capital social: notas provisórias. In: NOGUEIRA, Maria Alice; CATANI, Afrânio Mendes. Escritos de educação. Petrópolis: Vozes, 1998.

BOURDIEU, P. Razões práticas: sobre a teoria da ação. Campinas: Papirus. 1996.

BOURDIEU, P.; WACQUANT, L. Réponses. Paris: Seuil, 1992.

BOURDIEU, P. El mercado lingüístico. In: BOURDIEU, P. Sociología y cultura. Miguel Hidalgo: Grijalbo-Consejo Nacional para la Cultura y las Artes,2002. p. 143-158.

CATANI, A. C. et al. Vocabulário Bourdieu. Belo Horizonte: Autêntica, 2017.

COAKLEY, J. Sports in society: issues and controversies. 10. ed. New York: McGrawHill, 2008.

LANCIEN, D.; SAINT MARTIN M. Anciennes et nouvelles aristocraties de 1880 à nos jours. Paris: Maison des Sciences de'l homme, 2007. Disponível em: http://search.ebscohost.com/login.aspx?. Acesso em: 21 jan. 2019.

MARCHI JÚNIOR, W. Bourdieu e a teoria do campo esportivo. In: PRONI, M. W.; LUCENA, R. F. Esporte: história e sociedade. Campinas: Autores associados, 2002. p. 77-111. 
MARCHI JÚNIOR, W. Sacando o voleibol. Hucitec: Unijuí, 2004.

MARQUES, R. F. R.; GUTIERREZ, G. L. O esporte paralímpico no Brasil: profissionalismo, administração e classificação de atletas. São Paulo: Phorte, 2014.

MARQUES, R. F. R. Contribuições da obra de Pierre Bourdieu para a pesquisa em sociologia do esporte no Século XXI. In: BETINNE, Marcos (Org.). Estudos interdisciplinares em sociologia do esporte. São Paulo: Escola de Artes, Ciências e Humanidades, 2015. p. 9-37.

MARQUES, R. F. R. et al. Esporte olímpico e paraolímpico: coincidências, divergências e especificidades numa perspectiva contemporânea. Revista brasileira de educação física e esporte, São Paulo, v. 23, n. 4, p. 365-377, 2009.

ORTIZ, R. Mundialização e cultura. 2. ed. São Paulo, Brasiliense, 1994.

RICHTER, K. J. et al. Integrated swimming classification: a faulled system. Adapted Physical Activity Quarterly, Champaign, v. 9, p.5-13, 1992.

SALVINI, L.; SOUZA, J.; MARCHI JÚNIOR, W. A violência simbólica e a dominação masculina no campo esportivo: algumas notas e digressões teóricas. Revista Brasileira de Educação Física e Esporte, São Paulo, v. 26, n. 3, p. 401-410, 2012.

SOUZA, J.; MARCHI JÚNIOR, W. As linhagens da sociologia do futebol brasileiro-um programa de análise. Movimento, v. 23, n. 1, p. 101-118, 2017.

SOUZA, J.; MARCHI JÚNIOR, W. Por uma sociologia reflexiva do esporte: considerações teórico-metodológicas a partir da obra de Pierre Bourdieu. Movimento, Porto Alegre, v. 16, n. 1, 2010.

STIGGER, M. P. Esporte, lazer e estilos de vida: um estudo etnográfico. Forward Movement, 2002.

THIRY-CHERQUES, H. R. Pierre Bourdieu: a teoria na prática. Revista de Administração Pública, Rio de Janeiro, v. 40, n. 1, p. 27-55, jan./fev. 2006.

WACQUANT, L. J. D. O legado sociológico de Pierre Bourdieu: duas dimensões e uma nota pessoal. Revista de Sociologia e Política, Curitiba, n. 19, 2002. 